\title{
L’Église au diocèse de Chicoutimi. Survol : 1535-1988
}

\section{Marius Paré}

Volume 55, 1988

Cent cinquante ans d'histoire religieuse au Saguenay-Lac-Saint-Jean (1838-1988)

URI : https://id.erudit.org/iderudit/1006950ar

DOI : https://doi.org/10.7202/1006950ar

Aller au sommaire du numéro

Éditeur(s)

Les Éditions Historia Ecclesiæ Catholicæ Canadensis Inc.

ISSN

0318-6172 (imprimé)

1927-7067 (numérique)

Découvrir la revue

Citer cet article

Paré, M. (1988). L’Église au diocèse de Chicoutimi. Survol : 1535-1988. Sessions d'étude - Société canadienne d'histoire de l'Église catholique, 55, 119-148.

https://doi.org/10.7202/1006950ar

Tous droits réservés @ Les Éditions Historia Ecclesiæ Catholicæ Canadensis Inc., 1988
Ce document est protégé par la loi sur le droit d'auteur. L'utilisation des services d'Érudit (y compris la reproduction) est assujettie à sa politique d'utilisation que vous pouvez consulter en ligne.

https://apropos.erudit.org/fr/usagers/politique-dutilisation/ 


\title{
L'Église au diocèse de Chicoutimi Survol: 1535-1988
}

\author{
Mgr Marius PARÉ \\ Chicoutimi, Qué.
}

La population de notre région du Saguenay-Lac-Saint-Jean célèbre présentement le $150^{\mathrm{e}}$ anniversaire de son établissement sur les rives de la rivière qui est une partie de son cœur, le Saguenay. La Société canadienne d'histoire de l'Église catholique, à cette occasion, a eu la délicate et généreuse idée de tenir sa session annuelle parmi nous et de prendre ainsi part à notre célébration. Elle veut évoquer avec nous ce que l'Église catholique a accompli ici durant ces années. Nous lui en exprimons notre vive reconnaissance.

La population francophone s'est établie sur les rives du Saguenay il y a cent cinquante ans. Le responsable de la session nous a demandé d'en donner un aperçu. Mais l'Église est présente dans cette partie du pays depuis beaucoup plus longtemps et nous ne pouvons l'ignorer. On nous permettra donc de remonter à l'apparition du premier missionnaire sur le territoire du futur diocèse de Chicoutimi à Tadoussac en 1535. L'ensemble de notre exposé ne peut être qu'un survol, un survol qui ne manque pas d'intérêt certes, mais qui a l'inconvénient d'être schématique, par conséquent moins concret et vivant. Nous nous exécutons cependant très volontiers, convaincu qu'une vue d'ensemble de l'histoire de l'Église au Saguenay-Lac-Saint-Jean ne manque pas d'avantages.

Nous disons et écrivons que Dieu est le Maître de l'Histoire et c'est juste car il est le Maître absolu de l'univers ou du cosmos et de la vie qui y existe. Il en est le créateur et la fin. L'intelligence et la liberté dont il a gratifié l'homme peuvent apparemment lui faire obstacle, mais elles sont dans son plan providentiel et ne l'empêchent jamais de parvenir à ses fins. À plus forte raison est-il le Maître de l'Histoire de l'Église, cette société fondée par son Fils, le Christ Jésus, qui l'a confiée à ses apôtres en leur disant: «Tout pouvoir m'a été donné au ciel et sur la terre. Allez donc, de toutes les nations faites des disciples, les baptisant..., et leur apprenant à 
observer tout ce que je vous ai prescrit. Et moi, je suis avec vous pour toujours, jusqu'à la fin du monde» (Matt. 28, 18b, 19 et 20). L'histoire de l'Église, c'est l'histoire de ce que Dieu a accompli à travers le temps par les hommes et les femmes qui ont adhéré à Lui et à la révélation par la foi, la confiance et l'amour reçus gratuitement au moment du baptême, qui ont été fidèles à l'envoi de la confirmation précisé par les sacrements de l'ordre ou du mariage ou d'un mandat particulier de l'Église. Par là même, l'Histoire de l'Église a des critères, des points de repère et des contours qui lui sont propres. C'est dans cette optique que nous présentons un survol de l'histoire de l'Église vécue par la population du territoire qui sera celui du diocèse de Chicoutimi en 1878 , donc des comtés provinciaux actuels de Charlevoix, Saguenay jusqu'à Rivière-Portneuf, Dubuc, Chicoutimi, Jonquière, Lac-Saint-Jean et Roberval.

Nous divisons notre exposé en cinq parties:

1. Le premier peuple de Dieu: les Montagnais: 1535-1838

2. Un nouveau peuple de Dieu: les colons de Charlevoix et de la Province; c'est la naissance d'une Église particulière ou diocèse: 18381878

3. La fondation et consolidation du diocèse: $1878-1892$

4. La vie en pleine maturité: $1892-1960$

5. L'époque contemporaine: $1960-1988$

I

Le premier peuple de Dieu: les Montagnais: $1535-1838$

Tadoussac était pour les Indiens qui faisaient le commerce des fourrures un lieu privilégié de rencontre. À chaque été, ils se retrouvaient là nombreux pour échanger leurs marchandises. Dès l'apparition des visages pâles au pays du Canada, Tadoussac fut un port préféré où s'arrêtaient les vaisseaux transatlantiques qui remontaient le Saint-Laurent. Pour les commerçants et les missionnaires qui voulaient pénétrer à l'intérieur des terres, ce fut aussi la porte d'entrée. Cartier s'y arrête au début de septembre 1535 avec ses trois vaisseaux, la Grande et la Petite Hermine et l'Émérillon. Sur les vaisseaux de Cartier il y avait toujours un prêtre séculier ou régulier pour desservir l'équipage. Ce prêtre ne manqua pas l'occasion d'entrer en contact avec les Indiens, car l'évangélisation était au programme du grand explorateur. C'est le début de l'histoire de l'Église au Saguenay.

Les Montagnais à cette époque étaient dix mille environ. Ils habitaient le territoire avoisinant les deux rives du Saguenay, la région du Lac-Saint-Jean et de la haute Mauricie jusqu'aux approches de la baie de James. Parmi les Indiens, les Montagnais étaient la tribu la plus 
accueillante à la foi en Dieu. Le père Lucien Campeau, S.J., qui a fait des études particulières en ce domaine, en arrive à la conclusion que quatre missionnaires chez les Montagnais ont fait plus de conversions que onze chez les Hurons. La grande difficulté qu'ils rencontraient cependant était de les suivre durant les saisons froides de l'année; à ce moment, ils devenaient nomades dans les forêts.

En réalité, l'évangélisation proprement dite du peuple montagnais commence en 1615 avec l'arrivée de quatre franciscains récollets en compagnie de Champlain: les pères Denis Jamet, Jean Dolbeau, Jean Le Caron et le frère Pacifique Duplessis. Après un premier contact encourageant au cours de l'escale à Tadoussac, ils repartent pour Québec, le lieu de leur destination. Le père Jean Dolbeau revient à l'automne et circule pendant deux mois avec eux dans la forêt. À ce titre, nous le considérons comme le premier de nos missionnaires. Malheureusement, il ne peut soutenir plus longtemps les inconvénients de la fumée dans les tentes; il est menacé de perdre la vue. Le père Le Caron est le plus assidu à revenir, mais ses visites sont encore trop espacées pour que l'œuvre prenne racine et consistance. Le travail reviendra aux Jésuites qui sont de retour au pays en 1632.

Le père Paul Lejeune se présenta à Tadoussac en 1633 et passa l'hiver en forêt avec les Montagnais. Plusieurs fois, il crut que sa dernière heure était arrivée, ce qui eut comme conséquence que, pour lui, si on voulait vraiment évangéliser ces nomades, il fallait les entraîner à la vie sédentaire comme on l'avait fait avec les Hurons. Il revient à Québec et demeure en attente. C'est un Montagnais qui renverse la vapeur. Charles Meiachkawat, une sorte de mystique, vient à Québec implorer le père Barthélémy Vimont, le nouveau supérieur, de leur retourner le père Le Jeune. Il garantit le succès. Le père consent à revenir en 1641 et réussit assez pour en conduire plusieurs au baptême après un mois de travail. Mais il ne peut se résoudre à passer l'hiver avec eux dans la forêt. À partir de cette date, 1641, jusqu'en 1782, il y eut toujours un ou plusieurs jésuites missionnaires dans la région. Trente d'entre eux se succédèrent ainsi. Il n'est pas possible ici de raconter cette histoire magnifique malheureusement trop ignorée, mais nous tenons à signaler au moins ceux qui l'ont le plus marquée.

Au père Le Jeune, qui fut l'initiateur méritant, succède le père Jean de Quen, qui vient et revient de 1642 à 1653, bâtit une chapelle et une résidence à Tadoussac en 1643, découvre le lac Saint-Jean en 1647 alors qu'il se rendait chez les Porcs-Épics aux prises avec une épidémie, à l'embouchure de la rivière Métabetchouane; il est le premier blanc à remonter le Saguenay et les rivières que suivent les Indiens pour se rendre au lac Saint-Jean. 
Le père Gabriel Druillettes est un homme plein de ressources, à l'âme très surnaturelle, d'une générosité qui exclut tout calcul, thaumaturge au besoin. Il vient à plusieurs reprises de 1645 à 1670. Nous devons lui rendre hommage, car c'est lui qui fait la preuve que le missionnaire peut passer l'hiver avec les Indiens et donner à la religion des Montagnais son caractère nomade.

Le père Charles Albanel fait deux séjours comme responsable, de 1653 à 1661 et de 1669 à 1671 . C'est un personnage un peu versatile mais d'un potentiel extraordinaire, d'un courage et d'une énergie sans pareils. Rien ne l'arrête. Il fait à deux reprises le voyage à la baie d'Hudson par le lac Saint-Jean et ses affluents, voyage que tous considèrent comme humainement impossible. Il fait le premier en 1671, à la demande de l'intendant Talon et avec le consentement de son supérieur, le deuxième en 1673 à la demande du gouverneur Frontenac. Le deuxième est particulièrement pénible. Il se termine par son emprisonnement chez les Anglais de la baie d'Hudson et un séjour en Angleterre. Libéré en 1676, il revient au pays et meurt dans l'Illinois, âgé de plus de quatre-vingts ans.

Le père François de Crespieul est l'un des plus méritants parmi les méritants. Intelligence lucide, caractère ferme et droit, vie intérieure d'une rare qualité et constitution physique robuste. Pendant au-delà de trente ans, de 1671 à 1703, il parcourt annuellement le territoire qui va de l'île aux Coudres à Sept-l̂les sur la côte et de Tadoussac au grand lac Mistassini à l'intérieur. Il construit quatre chapelles: Moisie, Chicoutimi, Métabetchouan et Micabeau à la source de la rivière Chamouchouane. Il est un des grands missionnaires de l'Église au Canada. Il fut admirablement servi par le frère François Malherbe, religieux d'une «haute vertu», au dire du père de Crespieul.

Après le père de Crespieul, il y eut un déclin; l'on manquait de missionnaires. Quand arrive le père Pierre Laure en 1720, la mission est dans un état pitoyable. Le nouveau responsable a la réputation d'être ouvert à tout ce qui est grand et beau et de vivre une mystique que rien ne rebute. C'est un artiste. Il a du talent pour la peinture et la décoration. Il le démontre quand il remplace la chapelle que le père de Crespieul a construite à l'embouchure de la rivière Chicoutimi et qui tombe en ruine, par une autre qu'il édifie avec soin et qu'il décore lui-même avec piété. Il peint tout particulièrement un magnifique Christ en croix qu'il place audessus de l'autel. Cette peinture est conservée aujourd'hui à la vieille maison des jésuites à Sillery. Il cultive l'ethnographie, la géographie et la cartographie. Il a laissé des cartes de la région qui sont considérées comme les meilleures du temps. Ces qualités de l'intelligence et du cœur, il les met au service de ses missions qu'il suit avec méthode et précision jusqu'à 
sa mort qui vient le cueillir prématurément à l'âge de cinquante ans aux Éboulements.

Le père Claude-Godefroy Coquart prend la relève en 1746 . Il vit au Saguenay les jours troublés de la fin de la domination française et rend de très grands services au peuple montagnais en lui servant d'intermédiaire auprès des nouveaux maîtres avec qui il entretient d'excellentes relations. C'est lui qui a construit la chapelle de Tadoussac qui existe encore et où il repose. Il meurt à Chicoutimi en 1765 assisté seulement d'un jeune employé du poste, François Verreault, qui lui lit les prières des agonisants.

Il a comme successeur en 1766 le père Jean-Baptiste de la Brosse, lui aussi l'un des plus grands missionnaires de la Nouvelle-France dont le père Léo-Paul Hébert vient de publier une magnifique biographie. C'est un apôtre supérieurement doué et instruit, mais surtout un saint dont le peuple a fleuri la vie de ses légendes. Le territoire qui lui est confié est immense. À celui du père de Crespieul, l'évêque, monseigneur Briand, ajoute la Gaspésie et l'Acadie. Il vit la suppression des jésuites en 1773, contrôle sa souffrance et continue comme si de rien n'était sous la juridiction de l'évêque de Québec. Il a beaucoup écrit pour les montagnais: livres de prière, catéchisme, traduction de la Bible, grammaire, dictionnaire, etc. Il décède à Tadoussac en 1782 et est inhumé dans la chapelle près de son prédécesseur, le père Coquart.

Avec la disparition du père de la Brosse se termine la splendide épopée missionnaire des jésuites au Saguenay-Lac-Saint-Jean. Depuis la suppression de la compagnie, ces missions étaient revenues sous la dépendance immédiate de l'évêque de Québec. Comme les prêtres séculiers étaient peu nombreux, 143 pour tout le diocèse qui comprend une grande partie de l'Amérique du Nord, il ne peut envoyer pour entretenir la mission que des prêtres déjà attachés à un ministère régulier. Ils ne vinrent donc que durant une période de l'été. Quinze prêtres se dévouèrent ainsi. Ils vinrent du Séminaire de Québec, de Charlesbourg, de Loretteville, de Rimouski, de l'Isle-Verte, de la Beauce et se succédèrent de 1782 à 1844. L'abbé François-Gabriel Le Courtois, curé de Rimouski, vint pendant quinze ans, Charles-Joseph Primeau, curé de Saint-François de Beauce, pendant neuf ans, Jean-Joseph Roy, professeur au Séminaire de Québec, et François Boucher, curé de Loretteville, pendant dix ans. Ce dernier surtout eut du succès; le père Flavien Durocher, o.m.i., qui lui succéda lui en rend témoignage. Il reste cependant que la qualité de la foi et de la ferveur des montagnais diminua considérablement, au point que les pères oblats qui arrivent en 1844 devront entreprendre une nouvelle évangélisation. 


\section{Un nouveau peuple de Dieu \\ 1838-1878}

En 1674, le roi Louis XIV avait fermé la région qui nous intéresse à tout établissement agricole ou autre. Il l'avait déclarée «domaine royal» réservé au commerce des fourrures dont une partie des profits allait au trésor du roi. À la conquête, les autorités anglaises avaient adopté la même conduite accordant les mêmes privilèges et les mêmes conditions à des compagnies qu se succédaient depuis i 760 . En 1838 , lá Cômpạañic de la baie d'Hudson détenait le monopole et le bail conclu avec le gouvernement n'expirait qu'en 1842 mais était renouvelable.

\section{Premiers établissements}

Depuis plusieurs années, d'un peu partout dans la province, on réclamait l'ouverture de la région du Saguenay-Lac-Saint-Jean à la colonisation. Le gouvernement avait fait faire des études dont les conclusions étaient favorables, mais la décision d'ouvrir ne venait pas. Las d'attendre, vingt-et-un propriétaires et censitaires de La Malbaie décident de passer à l'action et de s'unir pour aider ceux de leur milieu qui veulent s'établir au Saguenay. La Compagnie de la baie d'Hudson leur accorde la permission de couper le bois et de le vendre à condition «de ne faire aucun commerce avec les Indiens, ni de couper, ni de faire paître le foin naturel». D'autre part, William Price, qui possède des moulins sur les rives du Saint-Laurent et aspire à profiter des forêts du Saguenay, s'engage à acheter leur bois. Forts de ces permissions obtenues et de cette aide de la Société des Vingtet-Un, au printemps de 1838, vingt-sept travailleurs de la forêt, dont plusieurs sont des colons potentiels apparaissent sur le Saguenay et se distribuent sur la rive sud aux Petites Îles près de l'anse Saint-Étienne, à l'Anse-aux-Cheval en face de la rivière Sainte-Marguerite, à l'Anse-SaintJean et à l'extrémité est de Baie-des-Ha!Ha! qui est l'objectif principal, et où ils sont au nombre de quatorze. Au cours de l'été, d'autres travailleurs arrivent et s'arrêtent sur la rive nord à la Descente-des-Femmes, aujourd'hui Sainte-Rose-du-Nord, à l'Anse-à-Pelletier non loin de la paroisse actuelle de Saint-Fulgence ou viennent s'ajouter au groupe de Baie-des-Ha!Ha! En octobre de la même année 1838, une goélette portant quarante-huit personnes, hommes, femmes et enfants, tous de La Malbaie excepté deux hommes originaires de Baie-Saint-Paul, arrivent à Baie-desHa!Ha! Les deux hommes de Baie-Saint-Paul se fixent à l'endroit de la paroisse actuelle de Saint-Alphonse. Ce dernier groupe arrive à l'automne, à l'approche de l'hiver. C'était un risque et, de fait, l'hiver fut pénible à cause surtout des installations construites à la hâte, insuffisantes pour affronter les rigueurs de notre saison. Il y eut trois mortalités: un homme et 
deux femmes. Ce qui les attrista le plus, ce fut l'absence d'un prêtre pour leur apporter le réconfort de la religion et les derniers sacrements.

Fort heureusement, au printemps, à l'ouverture de la navigation, leurs deux curés de La Malbaie et de Baie-Saint-Paul, les abbés Zéphirin Lévesque et Benjamin Decoigne, viennent passer quelques semaines avec eux. Ils s'arrêtent à tous les endroits où leurs paroissiens se sont établis, y élèvent une croix avec eux, leur donnent les sacrements de pénitence et d'Eucharistie, les aident à organiser leur vie spirituelle, le dimanche tout particulièrement. À l'Anse-Saint-Paul et à Baie-des-Ha!Ha!, ils demandent une chapelle et on leur conseille de la préparer. À Baie-des-Ha!Ha!, ils décident de se rassembler le dimanche chez Alexis Simard et font le programme de la réunion. Antoine Mailloux et André Bouchard sont chargés de l'enseignement du catéchisme.

Leur évêque, monseigneur Joseph Signay, en visite pastorale à La Malbaie en juillet de cette année 1839, pense à eux. Il leur adresse une lettre pastorale affectueuse et encourageante. En 1840, l'abbé Lévesque revient avec le curé de Sainte-Agnès, M. Godefroy Tremblay, et en 1841, l'abbé Louis-Alexis Bourret, nouveau curé de La Malbaie, reprend la coutume et vient bénir la chapelle de Saint-Alexis qu'ils viennent de terminer. Tout progresse. En 1842, le gouvernement ouvre le territoire à l'agriculture, rassure ces bonnes gens au sujet de l'avenir, met la paix partout et par là provoque la venue de colons de Charlevoix, de la côte sud du SaintLaurent et de divers endroits de la province. À Saint-Alexis, ils sont maintenant sept cents, et l'évêque leur envoie leur premier curé résidant, l'abbé Charles Pouliot. Ils entrent dans la vie paroissiale régulière.

\section{Les oblats de Marie Immaculée au Saguenay: 1844}

Vers ce temps, Peter McLeod, né d'un père écossais et d'une mère indienne, profitant de la liberté que lui donne son origine indienne, construit un moulin à scie à l'embouchure de la rivière qu'on appellera rivière du Moulin, et bientôt un second à l'embouchure de la rivière Chicoutimi, un kilomètre et demi en amont. Autour de ces deux moulins, de petits villages se développent. À ce moment, William Price, toujours aux aguets pour entrer au Saguenay, achète les installations de la Société des Vingt-et-Un qui est en difficulté financière et, à la faveur de l'ouverture de la région, s'associe à Peter McLeod. L'abbé Pouliot, malgré sa bonne volonté et son louable dévouement est bientôt débordé et s'en ouvre à son évêque en 1844. La réponse vient peu après. L'évêque nomme monsieur Pouliot curé de Saint-Irénée de Charlevoix et le remplace par les pères oblats de Marie Immaculée, arrivés au Canada en 1841, qui se déclarent intéressés aux missions chez les Indiens et en mesure de prendre charge de 
tout le ministère dans la région du Saguenay et sur la Côte Nord. Les pères oblats arrivent le 15 octobre 1844 à Grande-Baie qui sera le centre de leurs activités apostoliques. Ils sont quatre: Jean-Baptiste Honorat, le supérieur, Médard Bourassa, Pierre Fisette et Flavien Durocher, le frère de la future bienheureuse Marie-Rose Durocher. Une belle et forte équipe qui se partage le territoire à parcourir et les populations à évangéliser. Le père Honorat est un réalisateur. Fort physiquement, moralement et spirituellement, intelligent, il est plein d'imagination et d'initiative, d'un zèle que ricn nc paralyse. Monseigneur Turgeon, le coadjuteur de Québec, leur avait recommandé d'avoir «tous les égards possibles pour les membres de l'Honorable Compagnie de la baie d'Hudson, avec lesquels il est important que nous vivions continuellement en bonne intelligence». Mais il fallait compter aussi avec Peter McLeod et William Price. Monseigneur Turgeon avait prévenu le père Honorat que la chapelle construite par le père Laure en 1726, encore utilisée pour les Indiens, était très avariée et qu'il était urgent de la remplacer. Après examen de la situation le père en arriva à la conclusion qu'il était préférable d'en construire une nouvelle au village de Rivière-du-Moulin où se trouve le plus fort de la population. Mal lui en prit, car McLeod, protestant militant à ses heures, mijotait déjà le projet d'en élever une de sa confession, et la décision prise sous l'influence du père avait presque l'allure d'une provocation, puisque l'endroit choisi pour cette chapelle catholique était tout près de sa demeure. La lutte est très vive, car les deux hommes sont de vraies forces de la nature. McLeod doit céder finalement, car la population entière appuie le père Honorat. Mais le ressentiment demeure. Le feu s'embrase de nouveau quand la question d'une chapelle se pose aussi pour le village de la rivière Chicoutimi. Comme les deux concentrations sont appelées à former bientôt une seule paroisse, le père Honorat et l'abbé Jean-Baptiste Gagnon, le futur curé que monseigneur Turgeon lui a envoyé, décident de construire une église au centre pour favoriser la jonction. McLeod doit encore céder. Le père qui reçoit en plus les doléances des ouvriers et de la population, se met à concevoir un plan qui libérerait son peuple de cette dépendance générale et outrée des maîtres de l'économie régionale. Il se fait prêtre colonisateur, dirige des colons vers le canton Laterrière, fait avec quatre associés l'acquisition de douze lots, construit une chapelle, monte une scierie et une moulange. Nécessairement, il engage sa congrégation mais elle l'approuve. De l'extérieur, il a des approbateurs enthousiastes, comme l'abbé Louis Proulx de l'archevêché de Québec, mais aussi des opposants dont les principaux étaient Perter McLeod et même William Price qui voyaient en cette entreprise une concurrente qui n'était pas sans danger pour leur avenir. Ils agirent auprès de l'archevêque par personnes interposées. L'évêque, de plus en plus inquiet de l'aspect financier de l'entreprise, demanda le rappel du père en 1849. 
Le bon père Honorat se soumit, tout en affirmant qu'il n'y avait pas lieu de craindre si on lui donnait le temps nécessaire. Tout démontre qu'il avait raison. Peut-être, cependant serait-il arrivé au but s'il avait procédé avec plus de douceur dans ses interventions. Le père Flavien Durocher le remplaça comme supérieur, la communauté décida de vendre les propriétés et il ne resta aucune dette. Mais en 1853, elle rappela ses religieux. «Ils ont assez souffert», conclut monseigneur Eugène de Mazenod, leur fondateur et supérieur général. Ils conservèrent toutefois les missions indiennes de la Côte Nord et du Saguenay-Lac-Saint-Jean et s'y dévouent encore en 1988. L'histoire doit conserver avec respect les noms des pères JeanBaptiste Honorat, Flavien Durocher, Charles Arnaud qui se dévoua pendant 64 ans, soit toute sa vie de prêtre, et Louis Babel pendant 57 ans.

\section{Vers le lac Saint-Jean}

Les terres de la région du Lac-Saint-Jean depuis longtemps aussi éveillaient les appétits de ceux qui voulaient se fonder un avenir pour eux ou leurs familles. Plusieurs essais furent tentés en ces années, mais le résultat fut médiocre. Celui qui réussit prit naissance sur la côte sud du SaintLaurent et se donna le nom de «L'Association des comtés de L'Islet et de Kamouraska pour coloniser le Saguenay». Le principal animateur de l'Association fut l'abbé François Pilote, procureur du Collège de SainteAnne-de-la-Pocatière, et le réalisateur du projet, l'abbé Nicolas-Tolentin Hébert, curé de Kamouraska, dont le père Pierre-Maurice Hébert, franciscain capucin, vient de publier une biographie remarquable et à jour. La fondation de cette colonie que l'on appelle aujourd'hui Hébertville, préparée avec soin, conduite avec tact et précision fut un succès. Le défrichement commence en 1848 avec 44 hommes. Avec le premier arbre, «un jeune pin», ils font une croix au pied de laquelle, l'abbé Hébert célèbre la messe le lendemain. Les travaux sont suspendus pour l'hiver. Au mois de mai 1849 , ils reviennent avec un attirail de chantier complet comprenant des chevaux et des vaches. Ils sont alors soixante-quinze. Partis en goélette de Kamouraska, ils font un voyage qui dépasse notre imagination. Ainsi, au lac Kénogami qu'ils veulent franchir dans sa longueur de 34 kilomètres, ils construisent un radeau de 40 pieds de longueur et 30 de largeur et y placent en ordre personnes, animaux, provisions et matériel. Quarante hommes placés autour manient les rames. Soixante voiles sont tendues et deux barges avec huit bons rameurs accélèrent la marche, et l'on s'éloigne lentement de la rive après avoir récité pieusement les litanies de la Sainte Vierge. Vingt-quatre heures après, l'on parvenait à destination sans incident désagréable ${ }^{1}$. Le travail est planifié et s'exécute en collectivité. Il dure quatre ans. La distribution des lots a lieu en 1854. Tous

\footnotetext{
1 L'abbé François Pilote: Le Saguenay en 1851, p. 86.
} 
reconnaissent le succès et l'attribuent après Dieu à monsieur Hébert tout particulièrement. Le groupe était choisi. Plus tard, en 1867, l'abbé Dominique Racine, alors vicaire forain de la région, en rendra témoignage à son archevêque, monseigneur Baillargeon; "Cette paroisse, écrit-il, est la meilleure du Saguenay par son esprit de foi et de religion». Elle sera pendant plusieurs années aussi la porte d'entrée et le chef-lieu du Lac-SaintJean.

\section{Arrivée à C'hicoutimi de l'ab̉̉ Ḋominique Racine: 18602}

La venue au Saguenay en 1862 de l'abbé Dominique Racine comme curé de Chicoutimi et vicaire forain de la région est un événement majeur. Sans diminuer les mérites de qui que ce soit, surtout de son prédécesseur et premier curé de Chicoutimi, l'abbé Jean-Baptiste Gagnon, qui fut un vrai missionnaire dans la région pendant treize années, Dominique Racine, par un ensemble de qualités exceptionnel, allait exercer sur la population entière un ascendant tel qu'on ne fera plus rien sans lui.

Dès les jours qui suivent son arrivée, il se donne activement à ce qui lui paraît le plus urgent dans le ministère qui lui est confié: l'éducation. On lui offre la présidence de la commission scolaire en remplacement de l'abbé Jean-Baptiste Gagnon; il accepte. Appuyé par les commissaires, il invite les religieuses du Bon-Pasteur de Québec à venir à Chicoutimi diriger un couvent. En septembre 1864, cinq religieuses et une laïque en prennent charge et y reçoivent 86 élèves dont 35 pensionnaires et 18 demi-pensionnaires. C'est le commencement d'une grande œuvre, car l'éducation est le grand facteur du développement humain.

Tout heureux de ce qu'il vient d'obtenir pour les jeunes filles, l'abbé Racine se tourne vers les garçons. Ce dont ceux-ci ont besoin, c'est d'un collège avancé, car le cours élémentaire est assez bien organisé. L'idée d'un séminaire lui vient vite à l'esprit. En effet, l'on est loin des centres et peu de jeunes accèdent à l'université. Il en est là quand survient l'épreuve terrible du grand feu de 1870 , qu'il n'a certainement pas mis au programme. De la colonie de Saint-Félicien à Baie-des-Ha!Ha! c'est la grande désolation. «Cinq mille personnes sont sans abri, sans nourriture, sans vêtements, ayant tout perdu ou à peu près.» Ce fut une tâche immense que celle de secourir tous ces malheureux.

Et cependant, l'abbé Racine, malgré le travail abondant que lui imposent le soutien et le secours à apporter à cette population dans son rétablissement, pense aussi à son séminaire. Encouragé par monseigneur Elzéar-Alexandre Taschereau, son archevêque depuis 1870, qui a fait de lui son vicaire général pour la région du Saguenay-Lac-Saint-Jean, il prend la décision d'ouvrir dès que possible un Grand et un Petit Séminaire 
à Chicoutimi. «Courage, Dieu est avec vous», lui écrit l'archevêque en lui conseillant de tout mettre sous la protection de saint Joseph. Grâce à la collaboration des commissaires, l'abbé Racine fait l'acquisition pour un dollar de l'école du Centre, l'agrandit et l'aménage en conséquence. Monseigneur Taschereau en fait la bénédiction le 28 juillet 1873 à l'occasion de sa visite pastorale, l'érige canoniquement le 15 août comme un Grand et un Petit Séminaire selon l'esprit du Concile de Trente, les met sous le patronage de la Sainte Famille, nomme l'abbé Racine supérieur, lui donne deux prêtres et un diacre comme collaborateurs, et l'institution ouvre ses portes le 15 septembre 1873 . Le nouveau séminaire accueillera au cours de l'année scolaire 61 élèves dont 13 pensionnaires. Mais cette première maison ne peut être que temporaire. Monseigneur Taschereau prévient l'abbé Racine, l'aide concrètement et efficacement à fixer définitivement et à construire sans retard le nouveau bâtiment près de l'église, vient en faire la bénédiction le 4 août 1875, et, le 7 septembre, prêtres et élèves occupent leurs nouveaux locaux.

Monseigneur Taschereau presse ainsi l'abbé Racine parce qu'il a maintenant la conviction, malgré les perplexités de celui-ci, qu'un diocèse dans la région est devenu nécessaire. L'église paroissiale ouverte au culte en 1849, construite en bois est minable. Il lui enjoint d'en construire une nouvelle. Le curé obéit et se met courageusement à l'œuvre. L'archevêque se tient près de lui, l'assiste et intervient avec assiduité et précision, car cette église sera une cathédrale. On ne fait que le gros œuvre, donc sans terminer l'intérieur, pour ne pas alourdir imprudemment la dette et compromettre le ministère pastoral par les tracas financiers. Le 28 mai 1878, le pape Léon XIII érige canoniquement le diocèse de Chicoutimi et nomme monseigneur Dominique Racine son premier évêque résidentiel.

\section{III}

\section{Fondation et consolidation du nouveau diocèse: 1878-1892}

Le territoire du nouveau diocèse, avons-nous déjà écrit, comprend les comtés provinciaux actuels (1988) de Saguenay jusqu'à la rivière Portneuf, de Charlevoix, de Dubuc, de Chicoutimi, de Jonquière, de Lac-SaintJean et de Roberval. Il compte 27 paroisses et une réserve montagnaise de 50 familles, une population catholique de 39300 fidèles, 35 prêtres séculiers et un prêtre religieux oblat de Marie Immaculée ${ }^{2}$. Le diocèse est érigé mais il est jeune et il faut le rendre à maturité. Nécessairement, cette œuvre fondamentale exigera plusieurs années d'un effort intense et persévérant.

\footnotetext{
2 Archives de l'Évêché de Chicoutimi, Monsieur F.-X. Frenette, secrétaire.
} 
L'ordination épiscopale de monseigneur Racine a lieu à la basilique cathédrale de Québec et lui est conférée par monseigneur Taschereau, son métropolitain. Le retour et l'intronisation à Chicoutimi se font en grand sous la présidence de monseigneur Taschereau qui bénit la cathédrale nouvellement construite et conduit le nouvel évêque au trône (cathèdre) avec monseigneur Laflèche, évêque de Trois-Rivières. Les célébrations publiques accomplies, les visites les plus urgentes effectuées, les émotions suffisamment résorbées, le nouvel évêque se retrouve comme auparavant et se remet au travail quotidien avec cette différence qu'il a des responsabilités accrues avec une autonomie qui l'obligent davantage. Nous ne pouvons ici qu'esquisser rapidement les principaux événements des neuf années et huit mois que dura son épiscopat.

Monseigneur Racine est un prédicateur populaire remarquable, intuitif et pratique. Que ce soit à la cathédrale, dans les paroisses, les communautés religieuses, que ce soit dans les circonstances spéciales, ses interventions et son enseignement ne sont jamais superficiels ni banals. Même quand il doit improviser, il est heureux. La communication l'inspire et l'anime, il se retrouve avec sa vraie personnalité et ses moyens qu'il fait valoir avec bonheur. Son peuple, quelle que soit la classe, ne se lasse pas de l'entendre, ce qui ne diminue pas ses activités.

Depuis des années, il rêve de consacrer la région à la Vierge Marie. Au cours d'un voyage sur le Saguenay, il a même pensé que ce pourrait être en érigeant une croix et une statue de la Vierge, celle-ci sur le premier, celle-là sur le deuxième des trois échelons du cap Trinité. En 1881, profitant d'une initiative de monsieur Charles-Napoléon Robitaille, voyageur de commerce de Québec, le rêve devient une réalité le 15 septembre. Par ce dimanche ensoleillé et une nombreuse assistance, il bénit une statue de vingt-cinq pieds représentant la Vierge Immaculée de Lourdes, érigée sur le premier degré du cap Trinité à six cents pieds au-dessus du niveau de la rivière Saguenay, et une croix en bois de cinquante-cinq pieds sur le deuxième, à huit cents pieds. Elles sont toujours là en 1988; nécessairement elles ont exigé des réparations au cours du temps. La croix a été renouvelée plusieurs fois.

L'éducation en famille et à l'école a toujours été une priorité pour monseigneur Racine. Au début de son épiscopat, le diocèse possède un Grand et un Petit Séminaire, trois couvents, l'un à Baie-Saint-Paul, tenu par la Congrégation de Notre-Dame, le deuxième à La Malbaie dirigé par les sœurs de la Charité de Québec et le troisième à Chicoutimi par le BonPasteur de Québec. Il a aussi des écoles élémentaires. Dans la région du Lac-Saint-Jean en plein développement durant ces années, il n'existe que les classes élémentaires. Un concours de circonstances favorables conduit l'évêque chez les ursulines de Marie de l'Incarnation à Québec. En mai 
1882, quatre religieuses ursulines arrivent à Roberval, accompagnées de l'évêque. Elles seront bientôt huit. La Supérieure est mère Saint-Raphaël (Malvina Gagné) qui accomplit une œuvre merveilleuse en concevant et réalisant une école ménagère agricole adaptée aux besoins de la région; elle servira d'inspiration et de modèle dans la province entière.

Évêque, monseigneur Racine était demeuré curé de la cathédrale et supérieur du séminaire. Il abandonne l'administration de la paroisse en 1880 et la confie à un curé d'office, monsieur Ambroise-Martial Fafard, qu'il introduit au séminaire en le nommant d'abord vice-supérieur, puis supérieur en 1882. Il peut alors se diriger vers Rome en septembre pour accomplir son devoir de visite ad limina apostolorum et présenter au pape son premier rapport sur l'état de son diocèse. Il revient en mars 1883 .

La région ne possède encore aucune maison hospitalière pour recevoir ses malades, ses infirmes et ses vieillards. Comme le gouvernement fédéral forme le dessein d'ouvrir un petit hôpital pour les marins qui viennent de partout en raison du commerce international du bois, monseigneur Racine, avec l'aide des députés Cimon et Gagné et du ministre Hector Langevin, finit par faire accepter du gouvernement qu'il soit confié à des religieuses et ouvert à la population. Les augustines de l'Hôpital Général de Québec en prennent charge en mai 1884. Elles sont quatre et la supérieur est mère Saint-Gabriel (Julie-Émélie Lamarre). Deux ans plus tard, les religieuses construisent une chapelle et ajoutent une aile au petit Hôpital de Marine.

En entrant dans le collège épiscopal du pays, monseigneur Racine, en dépit de sa mentalité et de sa répugnance, est forcé de se mêler aux questions litigieuses alors débattues dans l'Église du Québec. L'une d'entre elles oppose désagréablement les diocèses de Québec et de Montréal. L'Université Laval, fondée à Québec en 1852, a ouvert une succursale à Montréal en 1876. Monseigneur Bourget, jugeant Laval d'esprit trop libéral, veut l'indépendance et recourt à Rome. Monseigneur Taschereau croyait que tout se calmerait après une visite qu'il avait faite lui-même au centre de l'Église mais ce ne fut pas le cas. Il demande alors à monseigneur Racine, en qui il a une grande confiance, de bien vouloir faire le voyage à son tour et obtenir une décision claire et ferme. Malgré ses hésitations, celui-ci obéit à son métropolitain à qui il est profondément attaché, part en février 1885 et revient en mai. Le voyage est couronné de succès.

L'activité de monseigneur Racine se porte aussi sur l'avancement matériel de son peuple. Il s'occupe d'agriculture, de colonisation, de voirie, soutient les promoteurs du chemin de fer Québec-Lac-Saint-Jean et Chicoutimi, organise les paroisses, en fonde sept au cours de son épiscopat et en ouvre plusieurs autres à la colonisation. 
En 1887, il croit le temps venu de doter le diocèse d'un évêché. Il y intéresse son clergé et son peuple, en commence les plans et prépare la construction. Il y travaillait avec soin lorsqu'en octobre il est atteint d'une infection grave du foie. Le développement de la maladie se fait inexorable et rapide; il décède à l'hôpital le 28 janvier 1888. Dans le diocèse, la consternation est générale, profonde et sincère. L'on comptait tellement sur lui! Le cardinal Taschereau tient à lui rendre hommage en célébrant un service funèbre à la basilique de Québec et deux jours après, monseigneur Antoine Racine, évêque de Sherbrooke. son frère, préside les obsèques dans une cathédrale débordante de fidèles. «Il a fait des choses merveilleuses», atteste monseigneur Thomas-Étienne Hamel, vicaire général de Québec, dans son oraison funèbre.

\section{Monseigneur Louis-Nazaire Bégin, 2e évêque: $1888-1892$}

Monseigneur Louis-Nazaire Bégin est élu évêque de Chicoutimi le $1^{\text {er }}$ octobre 1888. Depuis son retour des études supérieures à Rome et à Innsbrück, il a vécu au Grand et au Petit Séminaire de Québec, puis à l'École Normale Laval de Québec dont il était le principal au moment de sa nomination à Chicoutimi. Le cardinal Elzéar-Alexandre Taschereau lui conféra l'ordination épiscopale à la basilique de Québec, le 28 octobre 1888 , et il prit possession de son siège de Chicoutimi le 7 novembre.

Monseigneur Bégin se met sans retard et pleinement dans le sillage de monseigneur Racine qu'il estimait sans réserve. Il reprend donc le travail en cours. Celui-ci au moment de sa mort préparait la construction d'un évêché. Il reprend la tâche et la rend à bonne fin, y engageant même son avoir personnel. Il en fait la bénédiction et l'occupe avec les personnes de l'administration, le 15 juin 1890.

Lui qui depuis son retour de Rome avait été professeur et éducateur était tout naturellement porté vers les maisons d'éducation, particulièrement le séminaire. Le milieu lui était familier. Il se réserve le supériorat et nomme l'abbé Ambroise-Martial Fafard, curé de Baie-Saint-Paul et vicaire forain de l'arrondissement. Constatant que le personnel du séminaire est trop à l'étroit dans le bâtiment construit par monseigneur Racine en 1874 et 1875 , il prend avec le conseil de la maison la décision d'y ajouter le corps central prévu par l'architecte Peachy de Québec et ajourné pour ne pas augmenter la dette imprudemment. En septembre 1891, la nouvelle construction est terminée et occupée à la grande satisfaction de tous.

Le chantier du séminaire était en pleine activité lorsque, après étude de la situation financière de la cathédrale, il décide de la terminer. Le 28 octobre 1891, il en fait solennellement la bénédiction et l'inauguration. Pour un intellectuel supposément peu entraîné à l'administration matérielle, 
ce n'était tout de même pas peu. Mais il n'oublie pas la vie intellectuelle et spirituelle. Il se fait lui-même professeur au Grand Séminaire et envoie à ses frais personnels deux jeunes prêtres aux études supérieures à Rome: MM. Elzéar DeLamarre et Alfred Tremblay.

Au printemps de 1890, les religieuses du Bon-Pasteur avec l'aide de monsieur Fafard, entrent dans une construction nouvelle qui double le logement de leur premier couvent. Les augustines hospitalières de l'HôtelDieu durant les années 1890-1891 ajoutent une aile à leur hôpital et les ursulines de Roberval remplacent leur premier monastère et couvent en novembre 1890. Partout l'évêque apporte son concours. À Baie-SaintPaul, l'abbé Ambroise-Martial Fafard, toujours actif et réalisateur, achète personnellement une maison de 60 pieds avec le terrain avoisinant, y ajoute deux étages et la revêt de briques; ce sera l'Hospice Sainte-Anne, qui recevra les personnes âgées et bientôt, dans une aile qu'il fait construire, des aliénés mentaux. Cet hospice sera peu après confié à une communauté religieuse naissante dont il devient le fondateur, les petites franciscaines de Marie que monseigneur Bégin reconnaît comme Institut diocésain en février 1892.

Peu après son arrivée, monseigneur Bégin s'occupe activement avec monseigneur Calixte Marquis, P.A., gérant de la colonisation pour les districts du Saguenay et du Lac-Saint-Jean, de la venue des trappistes à Mistassini. L'abbaye d'Oka patronne la fondation. Tout est prêt pour l'automne 1891 quand des événements majeurs imposent un retard.

C'est encore avec le concours de monseigneur Bégin que les pères oblats de Marie Immaculée s'installent à Pointe-Bleue et y construisent une vaste résidence d'où ils s'occupent non seulement de la réserve indienne locale mais des missions du haut Saint-Maurice et de la région nordique.

Et comment ignorer le talent, les convictions humaines et religieuses des pionniers de nos paroisses? N'ont-ils pas été les vrais artisans de notre peuple? C'est le moment de leur rendre hommage ici en signalant au moins quelques-uns d'entre eux.

Marguerite Belley de La Malbaie, restée veuve avec douze enfants, doit voir à leur établissement. Elle décide d'en installer quelques-uns au Saguenay qui s'ouvre. Elle laisse la terre familiale à l'aîné, quitte La Malbaie à l'été de 1851 avec deux autres de ses fils, franchit à cheval ou à pied les cent quarante-cinq kilomètres qui la séparent de la rivière aux Sables, le futur Jonquière, passe la belle saison avec eux à défricher le terrain acquis. Le résultat final sera que l'un se fixe à la rivière aux Sables, un autre à Laterrière, un troisième à Chicoutimi et un quatrième à Alma. 
Les débuts de l'Anse-Saint-Jean ont été très laborieux et lents. Nous lisons dans la précieuse documentation laissée par le premier curé, l'abbé Lucien Otis, dont monsieur Raoul Lapointe nous a présenté la biographie ce matin, le récit qu'il fait de son arrivée le 26 septembre 1861, vingt-trois ans après l'ouverture de la paroisse, parmi «les souches énormes» qui ornent encore le petit chemin qui conduit de la rivière à l'humble résidence réservée au prêtre. Il souligne surtout la belle et généreuse coopération qu'il rencontre chez ses paroissiens, en dépit de leur dénuement et de leur pcu d'instruction. Aussi, le progrès ne tarde-t-il pas à venir. Quelques années plus tard, un successeur de l'abbé Otis, l'abbé Sévérin Pelletier (1879-1901), a laissé lui aussi dans les archives de la paroisse une documentation rare par son abondance et sa belle tenue sur la construction d'une nouvelle église et d'un nouveau presbytère en 1890-1893. Une œuvre tout à fait singulière d'entente, de générosité et de ténacité. Tout est donné gratuitement: terrain, bois, pierre, travail. À quoi l'on ajoute une contribution en argent. L'accord est parfait entre tous. L'évêque, monseigneur Bégin, est de la partie; il approuve, encourage, participe même concrètement. Au terme, la dette n'est que de 600 \$ et elle est contractée auprès de la municipalité. L'œuvre est non seulement réussie matériellement et moralement, mais elle est belle. C'est la petite église que nous admirons en 1988, un siècle après sa construction. Tout heureux, monseigneur Bégin vient «par un chemin impraticable et un froid des plus rigoureux» passer Noël 1890 avec eux, bénit solennellement et l'église et les paroissiens et leur pasteur. La construction du presbytère suit dans le même esprit et constitue avec l'église et le paysage environnant un mariage parfait.

Exemple admirable encore de courage, de persévérance et d'intelligence dans la poursuite d'un but respectable au plus haut point que celui des quatre frères Fleury de la paroisse de Sainte-Anne qui, en 1879, ne craignent pas de franchir plusieurs fois à pied, avec armes et bagages, quarante-huit kilomètres pour atteindre la rivière Mistouk où ils ont décidé de vivre à l'avenir, ni de loger au début dans des cabanes d'écorce; ce sont les fondateurs de Saint-Cœur-de-Marie.

Exemple non moins digne de l'histoire que celui de Joseph et Pierre Gauthier dit Larouche, deux frères, et de leurs femmes Flavie et Célina Simard, deux sœurs, qui figurent parmi les premiers défricheurs de SaintGédéon, s'y sont établis avec leurs familles, abandonnent ces biens à leurs fils aînés, et, à 57 et 52 ans, se déclarent encore capables de faire de l'abatis et de la terre: ce sont les pionniers de Saint-Henri-de-Taillon. Ce qui est remarquable, c'est qu'ils ont fort bien réussi avec la grâce de Dieu en qui ils mettaient toute leur confiance. 
À Saint-Bruno, Anicet et Théophile Tremblay, venus en 1876 comme travailleurs de la forêt, décident de se faire colons. Quand ils reviennent pour mettre leur projet à exécution, ils doivent passer la première nuit à la belle étoile, indice de la force d'âme qu'il leur faudra déployer. Non seulement ils sont les pionniers de la paroisse, mais ils en sont l'âme dirigeante toute leur vie. De vrais chefs de file au plan religieux comme au plan civil. Les deux familles donnent chacune un prêtre à l’Église.

À Saint-Joseph d'Alma, Justine Alarie, femme de Damase Boulanger, premier résident, ancienne institutrice, intelligente, chrétienne dans l'âme et d'une charité «à vider la maison», obtient de l'évêque la permission de conserver le Saint-Sacrement chez elle à condition de s'en rendre responsable, de voir à l'entretien de cette chapelle domestique, de la lampe du sanctuaire et de fournir les ornements. Femme d'idées et de zèle, elle fait davantage. Le dimanche, elle réunit les gens des environs, anime la prière, récite le chapelet, lit l'évangile et enseigne le catéchisme. Tout se fait debout avec ordre et solennité.

À Saint-Félicien, le mouvement de colonisation prend effectivement son départ lorsque Louis Savard et Élisabeth Tremblay, originaires de Charlevoix, arrivent en 1870 avec leurs enfants. Les trois fils aînés s'établissent au «rang double» d'aujourd'hui et avant de commencer le défrichement se mettent à genoux, récitent le «Notre Père» et se mettent sous la protection divine. Bientôt une croix rustique apparaît dans la clairière. Le dimanche, madame Savard rassemble ceux qui veulent prier, leur dit «la messe en blanc», commente l'évangile, médite sur le Saint-Sacrifice, récite le chapelet.

En général, le dimanche, jour du Seigneur, est fort bien respecté. On tient à assister à la messe, même au prix de quelque effort. «Se rendre à la messe à pied, affirme monsieur Onésime Painchaud de Saint-Méthode, on trouvait que ce n'était rien, ça prenait une heure et quart, une heure et demie environ pour une distance de six milles.»

À Normandin, les quatre Laliberté de Sainte-Émélie de Lotbinière et Narcisse Picard de Québec font célébrer une grand-messe avant de se mettre en chemin. L'œuvre accomplie dans la nouvelle paroisse est loin d'être médiocre.

Tous ces exemples concrets et vérifiés font voir à qui veut voir la qualité de la foi et de la piété de beaucoup de ces pionniers qui ont bâti nos paroisses et notre peuple avec Dieu. Nous leur devons une vraie reconnaissance.

En 1891, monseigneur Bégin fait son voyage ad limina à Rome, du 11 février au 2 mai. À son retour, la rumeur circule qu'il sera bientôt nommé archevêque coadjuteur du cardinal Taschereau à Québec. La 
rumeur devient une réalité le 22 décembre au grand regret du diocèse entier qu'il avait conquis. Il demeure administrateur du diocèse jusqu'à l'arrivée de son successeur. Le 8 avril 1892, la décision de Rome est connue. Monseigneur Michel-Thomas Labrecque, directeur du Grand Séminaire de Québec, devient le troisième évêque de Chicoutimi.

\section{IV \\ En pleine maturité: 1892-1961}

En 1892, monseigneur Bégin laisse le diocèse bien établi. Sans doute, il reste beaucoup à faire, il en reste toujours, car l'évolution de la vie apporte constamment ses exigences. Mais nous constatons que c'est la vie normale d'un diocèse canadien qui a atteint sa maturité et qui est considéré tel dans l'Église du pays.

\section{Les évêques}

Trois évêques président à sa destinée durant cette période.

\section{Monseigneur Michel-Thomas Labrecque: 1892-1927}

Monseigneur Labrecque reçut l'ordination épiscopale du cardinal Elzéar-Alexandre Taschereau dans la basilique cathédrale de Québec le 22 mai 1892 et fut intronisé dans la cathédrale de Chicoutimi le 28 mai suivant. Il a été évêque de Chicoutimi pendant 35 ans. Aussi sa place est-elle considérable dans l'histoire de notre Église diocésaine. Nous en aurons déjà une idée en rappelant qu'il a fondé 34 paroisses, ordonné 175 prêtres pour le diocèse qu'il a visité 10 fois 3 . À son arrivée, le diocèse comptait environ 55500 catholiques; à sa démission en 1927, il en comptait $125000^{4}$. En même temps que le diocèse de Chicoutimi, le pape Léon XIII lui confia «temporairement» l'administration de la préfecture du Golfe Saint-Laurent. Il la conservera jusqu'en 1903, année au cours de laquelle elle sera remise aux pères eudistes, deviendra vicariat apostolique en 1905 et sera dirigée par monseigneur Gustave Blanche, C.J.M.

Monseigneur Labrecque prit une part active au Premier concile plénier du Canada tenu à Québec en 1909 sous la présidence du délégué apostolique, monseigneur Donato Sbaretti.

\section{Monseigneur Charles Lamarche: 1928-1940}

Le quatrième évêque de Chicoutimi, monseigneur Charles Lamarche, nous venait de Montréal où il était curé de la paroisse Saint-Stanislas. Élu

${ }^{3}$ Monseigneur André Simard, P.d'H., Les évêques et les prêtres séculiers au diocèse de Chicoutimi, 1878-1968, p. 32.

4 Monsieur F.-X.-Eugène Frenette, Monseigneur M.-T. Labrecque, p. 5. 
le 17 août 1928, il fut intronisé le 17 octobre et ordonné le lendemain par le cardinal Raymond-Marie Rouleau, o.p., archevêque de Québec, dans la cathédrale de Chicoutimi. Il arrivait au début de la crise économique et durant tout son épiscopat, il dut compter avec elle. En effet, la région du Saguenay-Lac-Saint-Jean fut profondément affectée. C'est dans des conditions matérielles difficiles qu'il fallut vivre et travailler. La vie spirituelle, dont la qualité dépend du sacrifice pour une grande part, n'en souffrit tout de même pas. Monseigneur Lamarche fonda 18 paroisses et ordonna 87 prêtres pour le diocèse 5 .

En face de la crise, l'Église seconda activement l'État, même sous certains rapports, fit davantage pour aider et soutenir le peuple. Au diocèse de Chicoutimi, comme en plusieurs autres diocèses du pays, on fonda une société de colonisation à laquelle l'évêque attacha un prêtre. Beaucoup de familles furent dirigées par elle vers des terres nouvelles. Au moins elles pouvaient y subsister. C'est ainsi que plusieurs paroisses furent ouvertes sur des territoires jusque-là fermés à l'agriculture. Aujourd'hui, les initiatives prises en ces années ne trouvent guère la faveur de beaucoup; il leur semble qu'elles l'ont été sans discernement et sans prévision de l'avenir. Quand nous sortons de leur contexte les décisions qui ont été adoptées sous son influence, nous pouvons arriver à une pareille affirmation. Durant la crise économique, nous comptions les sous, tandis qu'actuellement nous comptons à peine les dollars. Ceux qui ont connu ce temps de restriction savent que beaucoup de familles ont pu le traverser convenablement grâce à ces moyens alors employés. La terre au moins permettait de vivre à ceux qui consentaient à la travailler. Actuellement plusieurs de ces paroisses se vident ou sont fermées par le gouvernement, mais il reste qu'elles ont été le salut de beaucoup durant les années 1930-1940.

\section{Monseigneur Georges Melançon: 1940-1961}

Monseigneur Georges Melançon était curé de Saint-Frédéric de Drummondville quand il fut élu évêque de Chicoutimi le 21 mai 1940. Il prit possession de son siège le 23 juillet 1940 et fut ordonné le lendemain dans la cathédrale de Chicoutimi par le cardinal Jean-Marie Rodrigue Villeneuve, o.m.i., archevêque de Québec.

En 1940, le monde est en pleine guerre. Si inacceptable que ce soit, la guerre avec ses horreurs dénoue la crise économique. Dans notre région, elle provoque une activité industrielle et commerciale intense qui a comme conséquence une grande prospérité matérielle et une augmentation considérable de la population.Vers les années 1960, quand le marché du travail

5 Monseigneur André Simard, P.d'H., Les évêques et les prêtres séculiers au diocèse de Chicoutimi, 1878-1968, p. 40. 
devient saturé, cette augmentation s'arrête. En 1945, Rome érige le diocèse de Hauterive, aujourd'hui Baie-Comeau: le diocèse de Chicoutimi lui cède alors la partie de son territoire située dans le comté de Saguenay. En 1951, il est encore amputé du comté de Charlevoix qu'il remet non sans douleur à Québec de qui il l'avait reçu en 1878. Le diocèse de Chicoutimi n'en continue pas moins à croître pour toucher son plus haut chiffre de population atteint jusque-là: 265000 fidèles environ. Durant cette période de grande activité, monseigneur Melançon fonde 28 paroisses et ordonne 160 prêtres pour le diocèse ${ }^{6}$.

\section{La vie spirituelle durant cette période de 1892-1961}

Au long de ces années, le diocèse de Chicoutimi, grâce à son homogénéité, à la vitalité de ses familles, à des avantages matériels appréciables, à la foi et au zèle de ses prêtres et de ses apôtres religieux et laïcs qui ouvrent les esprits et les cœurs à l'action puissante de l'Esprit Saint, devient une communauté très vivante de foi, d'espérance et de charité. Fidèle aux enseignements et aux directives de l'Église, il entre dans les grands courants de vie spirituelle que Dieu fait passer en elle, mettant en évidence des réalités et des vérités de notre foi et de notre piété. Nous avons connu alors des années de grande ferveur eucharistique, de dévotion réparatrice au Sacré-Cœur, de piété envers la Vierge Marie, d'attachement à l'Église et à son chef, le Souverain Pontife. Peut-on aussi ne pas penser à ces campagnes vigoureuses et bienfaisantes pour combattre les fléaux de l'intempérance ou de la mauvaise littérature? Peut-on oublier les ferventes retraites, surtout au temps du carême et de l'avent?

Le diocèse a reçu encore au cours de ces années des apports précieux qui ont favorisé l'entretien ou le développement de cette vie spirituelle de qualité. Il accueille en 1892 les cisterciens de la stricte observance, dits trappistes, qui s'établissent à Mistassini, fondent un monastère qui deviendra un prieuré en 1904 et une abbaye en 1935; les servantes du Saint-Sacrement en 1903 qui, après un séjour chez les sœurs de NotreDame-du-Bon-Conseil, et un deuxième dans la maison Guay de la rue Racine, se fixent définitivement chez elles en 1906 sur l'avenue SaintSacrement à Chicoutimi; les pères Jésuites qui ouvrent une maison de retraites fermées, la Villa Saint-Ignace, à Val Racine en banlieue de Chicoutimi; les religieuses de l'Immaculée-Conception qui fondent la même œuvre à Chicoutimi en 1930 pour les femmes et les jeunes filles; les pères franciscains capucins qui prennent en 1925 la relève de l'abbé Elzéar DeLamarre au pèlerinage à Notre-Dame-de-Lourdes et à saintAntoine de Padoue à Lac-Bouchette et lui donnent un tel élan qu'ils reçoi-

${ }^{6}$ Monseigneur André Simard, P.d'H., Les évêques et les prêtres séculiers au diocèse de Chicoutimi, 1878-1968, p. 41. 
vent aujourd'hui chaque année 250000 pèlerins et publient le Messager de saint Antoine à près de 50000 exemplaires; les pères du SaintSacrement en 1947 à Alma, et les carmélites en 1957 à Dolbeau. Vraies faveurs du ciel car ces communautés constituent des foyers de vie spirituelle. Combien parmi les communautés religieuses masculines que nous venons d'énumérer et celles qui viennent se joindre à nous dans la pastorale paroissiale, les eudistes, les clercs de Saint-Viateur, les pères maristes, les montfortains, les assomptionistes, les rédemptoristes, les frères mineurs franciscains, les missionnaires du Sacré-Cœur, les oblats de Marie Immaculée, les cisterciens de Rougemont, la Fraternité sacerdotale procureront aux communautés religieuses féminines, elles aussi foyers rayonnants de vie en Dieu, des aumôniers qualifiés!

\section{L'action pastorale}

Le plus grand nombre des paroisses du diocèse est sous la direction du clergé séculier. Les religieux ont pris la charge de plusieurs d'entre elles au cours des années et sont d'un secours précieux pour inoculer la vie divine dans la famille diocésaine. Les pères eudistes sont à la paroisse du Sacré-Cour depuis 1903, les rédemptoristes à Notre-Dame-dePerpétuel-Secours de Desbiens depuis 1926, les pères montfortains à Sainte-Marie-Médiatrice, Jonquière, depuis 1941, les pères capucins à la paroisse de Lac-Bouchette depuis 1943, les pères du Saint-Sacrement à Saint-Sacrement, Alma, depuis 1947 et les pères maristes à Saint-Jean-dela-Croix à Dolbeau depuis 1962.

Nous nous devons de signaler ici la fondation en 1904 d'une communauté religieuse qui occupe une place particulière dans plusieurs secteurs de la vie spirituelle et de l'action pastorale de notre Église: les antoniennes de Marie. Elle a pris naissance au séminaire. Ses constitutions ont été rédigées par l'abbé Elzéar DeLamarre qu'elles reconnaissent comme leur fondateur. Les antoniennes de Marie sont présentes partout où le prêtre vit et travaille: au Grand Séminaire, au Petit Séminaire (résidence des prêtres), au Séminaire-Marie-Reine-du-Clergé, dans les presbytères et en pastorale paroissiale, dans les œuvres diocésaines, les missions lointaines et l'éducation.

\section{L'éducation}

Comment une Église peut-elle se maintenir et progresser sans prendre une part active à l'éducation? Chez nous dans le passé, cette part de l'Église a été considérable, elle a même été exagérée au dire de certains. L'Église devait d'abord remplir sa mission évangélisatrice. Elle en a en plus assumé une part considérable pour suppléer à la déficience des moyens dont disposait notre peuple. Au long de ces années qui vont de 
1892 à 1961, elle a continué à prendre ses responsabilités et ses initiatives tout comme auparavant, assurant à notre population entièrement chrétienne le bienfait de cette éducation qui répondait à sa foi, à ses aspirations et à ses besoins.

Monseigneur Dominique Racine avait fondé son séminaire en 1873. Ses successeurs ont toujours pris un soin particulier de cette institution essentielle pour assurer la relève sacerdotale et pour donner à notre peuple l'élite professionnelle chrétienne qui lui était nécessaire. En arrivant en 1892, monseigneur Labrecque, tout comme monseigneur Bégin, se réserve le supériorat afin d'être plus près du personnel et plus utile à l'institution. Le corps professoral, en cette fin du $\mathrm{XIX}^{\mathrm{e}}$ siècle et au début du $\mathrm{XX}^{\mathrm{e}}$ siècle, compte plusieurs personnalités remarquables dont l'influence s'étend non seulement dans le diocèse mais en province. L'abbé Victor-Alphonse Huard est devenu un maître reconnu en lettres, histoire et sciences naturelles. Il a déjà à son crédit une abondante bibliographie qui lui ouvre les portes de la Société royale du Canada. Il fonde en 1894 le Naturaliste Canadien, revue scientifique accréditée au pays et à l'étranger. L'abbé Elzéar DeLamarre, professeur de théologie morale, est un apôtre qui apparaît partout et qui suscite des œuvres qui demeurent, notamment son centre de la dévotion à saint Antoine de Padoue qui agit au loin, jusqu'aux États-Unis, grâce au Messager Saint-Antoine, sa communauté des antoniennes de Marie et le pèlerinage de Lac-Bouchette. L'abbé Joseph-Alfred Tremblay, professeur de théologie et de sciences sacrées pendant trente ans, est aussi un prédicateur «profond, clair et goûté» ici au diocèse et à l'extérieur, et un poète fécond sous le pseudonyme de Derfla. L'abbé Eugène Lapointe, professeur de philosophie, entreprend en ces années une œuvre sociale chez les ouvriers qui va faire de lui le père du syndicalisme catholique au pays. Enfin, l'abbé Narcisse Desgagné, professeur de rhétorique, est l'homme de la littérature, «le plus académique de nos écrivains», notera un jour monseigneur Edmond Duchesne, P.d'H.; il se fait remarquer par ses études critiques sur la langue et la littérature françaises. Il ne craint pas la discussion, voire la vraie polémique dont il ne sort pas vaincu généralement.

$\mathrm{Au}$ cours de son histoire, le séminaire a connu des heures douloureuses et des heures heureuses. Monseigneur Racine et monseigneur Bégin avaient construit les deux corps de bâtiments qui existent en 1895 et qui font le bonheur de ceux qui les habitent. Mais la chapelle définitive prévue dès le début en 1873 attend encore. Profitant du bon vent, monseigneur Labrecque, avec une souscription recueillie dans le clergé et le peuple fidèle du diocèse, la construit et l'inaugure solennellement en fin du mois d'août 1900. À cette occasion, il dépose, dans une chapelle latérale de cette nouvelle chapelle, le cœur du fondateur, monseigneur Racine, conservé jusque-là dans la voûte de l'évêché. Dans la même occasion, il 
réserve le quatrième étage au-dessus de la chapelle au Grand Séminaire. Chapelle et Grand Séminaire sont dans une aile construite à l'arrière du corps central, du côté sud-est. Mais, épreuve qui a marqué la vie de ce temps, le 24 juin 1912, un violent incendie réduit le tout en cendre. L'hôtel Saguenay, la cathédrale, le séminaire, le couvent du Bon-Pasteur, la résidence des antoniennes de Marie et plusieurs maisons avoisinantes ne sont plus que ruines. Grâce à monseigneur Labrecque, aux prêtres du séminaire parmi lesquels se détache la forte personnalité de monseigneur Eugène Lapointe, vice-supérieur de 1911 à 1914 et supérieur de 1914 à 1923, grâce aussi à la générosité des fidèles, le séminaire est rebâti sur la côte, un peu plus au sud, et figurera dans les années subséquentes parmi les meilleures institutions classiques de la province.

Depuis le début, le Grand Séminaire et le Petit Séminaire vivaient sous la même autorité et la même administration. Monseigneur Melançon, devant le nombre croissant des vocations, donne au Grand Séminaire son autonomie en 1950, le réorganise et l'installe chez lui en 1958, à la faveur d'une souscription populaire substantielle. De plus, monseigneur Melançon inaugure dans la province le système des externats classiques afin de donner à un plus grand nombre de jeunes l'accès aux études avancées. Avec les frères enseignants, il ouvre de ces foyers d'enseignement dans les centres d'Arvida, de Port-Alfred, de Jonquière, d'Alma et de Roberval. Jonquière donne naissance au Collège de Jonquière qui fut dirigé par les pères oblats de Marie Immaculée et Alma au Collège d'Alma confié aux frères maristes et à quelques prêtres séculiers. Monseigneur Georges Melançon, désireux encore de venir en aide aux ânés qui aspirent au sacerdoce, ouvre le Séminaire Marie-Reine-du-Clergé à Métabetchouan, au Lac-Saint-Jean, en 1956. Quant aux jeunes filles, durant ces années, elles peuvent bénéficier des écoles normales du Bon-Pasteur ouverte à Chicoutimi en 1907, des ursulines ouverte à Roberval en 1926, de la Congrégation de Notre-Dame à Baie-Saint-Paul en 1936, du BonConseil à Chicoutimi en 1947, des petites franciscaines de Marie à Dolbeau en 1952 et d'un collège classique que le Bon-Pasteur inaugure en 1947 à Chicoutimi.

Depuis 1892, de nouvelles communautés religieuses enseignantes sont entrées dans le diocèse dont l'une est fondée par l'évêque.

Pour les jeunes filles, monseigneur Labrecque en 1894 accueille les sœurs de Notre-Dame-du-Rosaire et, devant la difficulté d'obtenir d'autres communautés enseignantes, il fonde à l'évêché même, en cette année 1894, avec mademoiselle Françoise Simard, l'Institut des sœurs de NotreDame du Bon-Conseil. Il rédige lui-même les constitutions. La nouvelle communauté s'est développée au cours des années au point qu'elle en arriva à diriger plusieurs institutions de premier plan et à donner l'enseignement 
dans quarante-trois paroisses du diocèse. Dans la suite, monseigneur Labrecque reçoit encore les sœurs de Saint-Louis-de-France et les filles de Sainte-Marie-de-la-Présentation, monseigneur Melançon, les Sisters of Charity of Halifax et les religieuses des Sacrés-Cœurs de Jésus et de Marie.

Chez les garçons, monseigneur Labrecque fait appel aux frères maristes, aux frères de Saint-François-Régis, aux frères du Sacré-Cœur, aux frères de Jésus et aux frères des Écoles Chrétiennes; monseigneur Lamarche, aux frères de l'Instrüction chrétienne et aux clercs de SaintViateur, pères et frères; monseigneur Melançon, aux pères des SacrésCœurs de Jésus et de Marie, aux frères de Sainte-Croix et aux frères de la Charité. À l'éducation aussi faut-il rattacher les deux patronages de Jonquière et de Bagotville confiés aux spécialistes de ces œuvres que sont les pères de Saint-Vincent-de-Paul et deux institutions de réhabilitation: l'Institut LaChesnaie de Roberval et de l'Institut Saint-Georges de Chicoutimi administrés par les pères maristes. Enfin, nous nous devons de signaler la fondation, par le séminaire, de l'École moyenne d'agriculture à Chicoutimi en 1937.

Pour les enfants, garçons et filles, les petites franciscaines de Marie ouvrent, à Chicoutimi en 1931, un important orphelinat, qui dès les premiers jours reçoit quatre cents sujets. Oeuvre des plus marquées de la charité chrétienne et des plus méritoires.

\section{La pastorale hospitalière}

Durant ces années, les augustines de la Miséricorde de Jésus connaissent un développement exceptionnel de leur activité hospitalière. Leur Hôtel-Dieu de Chicoutimi atteint, par étapes successives, des dimensions et une spécialisation médicale qui en font l'un des grands hôpitaux de la province. En 1918, un groupe de religieuses détachées de la communauté de Chicoutimi fondent, à Roberval, l'Hôtel-Dieu Saint-Michel auquel elles annexent bientôt un sanatorium antituberculeux. L'augmentation rapide de la population, dans les années qui suivent la guerre de 1939-1945, provoque la décentralisation du service hospitalier. Les augustines de Roberval ouvrent l'Hôtel-Dieu du Christ-Roi à Alma en 1954, celles de Chicoutimi, l'Hôtel-Dieu de Notre-Dame-de-l'Assomption à Jonquière et l'Hôtel-Dieu du Sacré-Cœur à Dolbeau en 1955. D'autre part, les petites franciscaines de Marie qui dirigent déjà l'Hôpital Sainte-Anne à BaieSaint-Paul acceptent l'Hôpital psychiatrique Sainte-Élisabeth de Roberval, et les sœurs de Sainte-Marie-de-la-Présentation l'hôpital des malades chroniques à Métabetchouan.

Les maisons d'accueil pour les vieillards se sont aussi multipliées. Nous bénéficions alors de la charité des oblates franciscaines de Saint- 
Joseph, qui sont à Grande-Baie et à Alma, des sœurs de Saint-Joseph de Saint-Vallier à Roberval et des antoniennes de Marie à Jonquière.

\section{La pastorale sociale}

Léon XIII avait publié son encyclique sociale Rerum Novarum, la première charte chrétienne des travailleurs, en 1891. Ce sera l'un des grands mérites de monseigneur Labrecque et de ceux qui l'entourent, particulièrement de monseigneur Lapointe, P.A., non seulement d'accepter la doctrine sociale de l'Église mais d'en saisir l'urgence et d'avoir le courage de poser des actes concrets devant le développement de l'industrie et l'accroissement de la classe ouvrière dans nos centres. Ils ont été les pionniers dans notre province. Après un travail long et patient auprès des ouvriers et des patrons de la pulperie de Chicoutimi dirigée par monsieur Alfred Dubuc, surtout de la part de monseigneur Eugène Lapointe, P.A., l'on fonde, en décembre 1907, la Fédération ouvrière du Nord. Le 19 mars 1912, monseigneur Labrecque reconnaît officiellement cette fédération par une lettre circulaire à tous ses diocésains et nomme monseigneur Eugène Lapointe directeur général des œuvres sociales dans le diocèse. Deux mois après, le 18 mai, la fédération devient La Fédération ouvrière mutuelle du Nord. L'évêque se réserve la haute orientation et les grandes décisions. Cette initiative est à l'origine des futurs «Syndicats catholiques de la province de Québec» devenus aujourd'hui la Confédération des syndicats Nationaux (C.S.N.) ${ }^{7}$.

L'action sociale auprès des ouvriers de l'industrie se double bientôt d'une action correspondante auprès des agriculteurs, des colons et des travailleurs de la forêt qui eurent leur propre association et leur aumônier. Cette activité de l'Église auprès des travailleurs ne s'est pas ralentie au cours des années. La région est demeurée l'une des plus syndicalisées et des plus vivantes de la province.

L'Église a encore assisté à la naissance et soutenu la promotion de l'Union catholique des femmes rurales (U.C.F.R.) et des Cercles d'économie domestique, fusionnés dans la suite pour former la puissante AFEAS, qui est devenue l'un des mouvements sur lesquels nous nous appuyons pour donner à l'action sociale un caractère chrétien qui la met en mesure de produire dans les âmes les fruits bienfaisants de la justice et de la charité.

Enfin, c'est aussi à l'action apostolique de l'Église diocésaine que nous devons la fondation, sous la direction de l'abbé François Plourde, d'un service social pour l'enfance délaissée ou malheureuse, service qui est passé aujourd'hui sous la dépendance et la gérance de l'État.

7 Mandements des évêques de Chicoutimi, vol. 5, p. 308 et suivantes. 


\section{L'Action catholique - L'apostolat des laïcs}

Dans cette rétrospective de l'histoire de l'Église au Saguenay-LacSaint-Jean, nous ne pouvons ignorer la place qu'occupe au $\mathrm{XX}^{\mathrm{e}}$ siècle l'A.C.J.C., l'Action catholique et, en général, l'Apostolat des laïcs.

L'A.C.J.C. prend naissance au début du siècle à Valleyfield sous l'inspiration de l'abbé Lionel Groulx et se développe rapidement dans la province. Elle a mobilisé pendant une trentaine d'années, à l'intérieur de l'Église et au sein de notre peuple, heaucoup de jeunes parmi les plus qualifiés et les a mis au service de la cause par excellence, celle du Christ. Elle a connu des années de vie intense et a entretenu un idéal élevé et chrétien chez ses membres qui lui doivent d'avoir avancé dans la vie par des chemins qui n'étaient pas ceux de la médiocrité. L'Église et la société ont trouvé chez ces jeunes devenus adultes des serviteurs vrais et apôtres en toute circonstance.

Dès le début de son pontificat en 1922, le pape Pie XI s'intéresse à l'Action catholique. Il en est question dans 120 de ses écrits et de ses discours. Elle pénètre et s'organise un peu partout, surtout après que l'abbć Joseph Cardyn, prêtre belge, futur cardinal, lui eut donné une forme concrète que Pie XI accepte et qui fait fortune. Peu à peu apparaissent ici et ailleurs, chez les jeunes d'abord, la J.O.C., la J.E.C., la J.I.C., et la J.A.C., tant chez les garçons que chez les filles, chez les adultes: la L.O.C., la L.I.C., la L.A.C., et l'Apostolat laïc sur un plan plus large: les Ligues du Sacré-Cœur qui sont devenues dans la suite «les Chrétiens d'aujourd'hui», les Dames de Sainte-Anne qui sont devenues «les Femmes chrétiennes», très vivantes actuellement, la Ligue catholique féminine, le Renouveau chrétien, le Tiers-Ordre, très actif, la Saint-Vincent-de-Paul, etc. Monseigneur Charles Lamarche écrit une lettre pastorale en 1933 pour établir officiellement l'Action catholique dans le diocèse comme le demandait Pie XI. L'Action catholique a connu chez nous des jours glorieux. Elle a peiné, il ne pouvait en être autrement, mais a réussi. Elle a été dirigée et animée par des hommes compétents et a à son crédit des œuvres qui l'honorent. La revue Témoignages qu'elle a publiée pendant plusieurs années à coup de sacrifices n'était pas une publication quelconque. Plusieurs de ses membres ont exercé, en dehors des milieux de l'Action catholique, une influence bienfaisante et ont même occupé dans la société des postes clés où leur esprit chrétien a été bénéfique à notre communauté humaine.

C'est dans notre Action catholique, dirigée alors par l'abbé Gérard Bouchard, qu'est né en 1946 l'Institut séculier féminin La Milice du Rosaire, aujourd'hui l'Institut Notre-Dame, dont les membres, après avoir milité activement au sein de l'organisme, se dispersent dans la société 
selon leurs aptitudes et les circonstances. Ils portent, dans les milieux où l'Église n'est pas très présente, le témoignage de personnes consacrées au Seigneur.

À l'instar de l'Institut Notre-Dame, un autre institut séculier féminin, venu de l'extérieur celui-là, les oblates missionnaires de Marie Immaculée, exerce un apostolat presque semblable à Jonquière.

\section{La pastorale missionnaire}

L'Église du Christ est essentiellement missionnaire: «Prêchez l'évangile à toutes créatures», lui a-t-il prescrit en «retournant vers son Père» (Marc, 16,15). Les églises particulières ne peuvent l'ignorer. La nôtre s'est efforcée d'entendre l'appel du divin Sauveur et d'y répondre généreusement. L'Union pontificale missionnaire, la Propagation de la Foi, l'Oeuvre de Saint-Pierre-Apôtre, l'Oeuvre Pontificale missionnaire des Enfants ont toujours eu une place de choix dans nos préoccupations. Deux communautés essentiellement missionnaires, les sœurs de l'Immaculée-Conception et les pères blancs, missionnaires d'Afrique, ont une résidence dans le diocèse. Un comité diocésain d'animation missionnaire est en action permanente. Depuis le début du siècle, des missionnaires originaires de notre Église diocésaine, membres des communautés religieuses, de la Société des Missions-Étrangères du Québec, des Instituts séculiers ou, de plus en plus, du laïcat, partent dans toutes les directions de la terre pour l'évangélisation. Vers la fin de cette période, le chiffre dépasse deux cents et le diocèse s'apprête à ouvrir une mission au Chili en union avec la Société des Missions-Étrangères; elle sera alimentée par le clergé diocésain, par les religieuses de la Congrégation de Notre-Dame du Bon-Conseil, de l'Institut séculier Notre-Dame, par le laïcat et sera soutenue spirituellement et financièrement par la communauté diocésaine.

\section{V \\ L'église contemporaine}

1961-1988

Ici, il nous paraît plus utile de nous éloigner du concret de la vie en Église comme nous le faisons depuis le début de notre exposé pour porter notre attention sur l'évolution générale et profonde que les découvertes scientifiques et les succès de la technique ont provoquée dans notre société, particulièrement depuis la guerre de 1939-1945. Nous sommes entrés dans un monde nouveau et l'évolution continue à un rythme qui ne diminue pas d'intensité. Nous avons grand-peine à suivre et à nous ajuster sans perdre l'essentiel de notre foi et de ce à quoi elle nous oblige. L'ajustement est d'autant plus délicat et malaisé que les centres principaux 
d'information et de diffusion des idées directrices de la pensée, du sentiment et de la conscience des humains que nous sommes se sont déplacés pour une grande part. Les médias, par exemple, la télévision et la radio surtout, jouent un rôle prépondérant à ce point de vue.

Le pape Pie XII, à la fin de son pontificat, constatait avec inquiétude que l'Église se devait de prendre des initiatives pour mettre en place une pastorale qui réponde aux besoins de ce monde contemporain en mutation profonde et rapide où la foi et les mœurs, où les valeurs chrétiennes essentielles risquaient de perdre estime, mais il se sentait trop près du grand passage à l'au-delà pour entreprendre ce qu'il souhaitait. Il fallut l'arrivée de Jean XXIII en 1958, jeune pape de 77 ans, aux intuitions géniales, inspiré de l'Esprit Saint a-t-il confié, pour prendre la courageuse décision de réunir un concile général qui atteint et engage le peuple de Dieu dans son entier. Ouvert en octobre 1962, ce concile a tenu quatre sessions générales et de nombreuses réunions de commissions et de groupes, et s'est terminé en décembre 1965 sous Paul VI. Deux mille cinq cents évêques et de nombreux spécialistes de la doctrine et de la pastorale y ont pris part. Il nous a donné des textes de haute qualité comme tous souhaitaient. Paul VI a affirmé et répété qu'ils sont pour de nombreuses années la règle de vie qui oriente l'Église et son peuple dans ce monde nouveau où ils sont entrés.

En même temps que le concile et au cours des années qui ont suivi jusqu'à présent, les gouvernements des pays de l'Occident, devant la même évolution générale, se sont préoccupés de répondre à des situations nouvelles. Ils ont produit une législation qui a reflété la mentalité pluraliste de la société qu'ils dirigent, une législation plus libre, une législation «permissive» qui a fait de larges trouées dans le pan de la morale naturelle et évangélique jusqu'ici regardée comme sacrée et intangible. Qu'on pense au divorce, à l'avortement, à la vente des contraceptifs, etc.

Chez nous dans la province de Québec, ce fut ce que l'on a appelé «la révolution tranquille», tranquille parce qu'il n'y a pas eu de sang versé, mais révolution qui a troublé considérablement notre conception chrétienne de la vie.

C'est dans ce contexte que l'Église du Québec a été appelée à mettre en application les directives du concile. Nous étions un peuple baptisé à 99\% dont $85 \%$ dans l'Église catholique, peuple parmi les plus homogènes et croyants pratiquants de l'univers, fort de ses traditions ethniques et religieuses auxquelles il était profondément attaché. La révolution tranquille, profitant d'un temps de prospérité économique avantageux, nous a donné des lois sociales opportunes et bienfaisantes mais aussi, pour répondre à un monde qui se voulait pluraliste, des lois permissives qui ont porté atteinte aux valeurs morales essentielles promues par le Christ et son 
Église, l'Église de l'immense majorité de notre peuple, des lois qui loin de le soutenir l'inclinent à oublier son baptême et le font glisser vers le matérialisme, elle nous a donné particulièrement un système d'éducation unifié qui a ouvert aux jeunes et à des moins jeunes des avenues et des carrières inconnues ou peu expérimentées jusque-là, mais aussi un système qui a mis l'Église, la grande éducatrice et enseignante chrétienne de toujours, dans une position nouvelle et curieuse. Là où elle était responsable à plein temps de l'éducation et de la formation chrétienne, elle s'est trouvée du jour au lendemain dans une dépendance entière de l'État et à l'arrière-plan du système. Elle jouit toujours d'une liberté entière et n'est aucunement brimée en ce qui touche l'enseignement religieux, mais elle est enfermée dans des structures qui limitent considérablement son pouvoir d'action et plus encore son influence, alors que l'éducation pour être efficace exige une présence et une affirmation constante de la parole et du style de vie.

C'est dans ces conditions difficiles que l'Église a présenté et appliqué les directives du concile qui nécessairement n'allaient pas, elles aussi, sans des ajustements aux besoins nouveaux, par conséquent sans provoquer des changements. Nous avons pensé qu'il fallait procéder sans retard, car ces directives du concile étaient censées projeter de la lumière sur les situations nouvelles nées des transformations sociales et apporter les indications nécessaires à tous les baptisés soucieux de sauvegarder leur foi et même aux gens honnêtes respectueux des valeurs naturelles. Mais déjà la confusion était entrée dans les esprits et continuait à s'aggraver. Évolution sociale, révolution tranquille, lois civiles et prescriptions mal comprises du concile se sont amalgamées en un tout qui a suffi à un bon nombre de baptisés pour fixer à l'avenir la conduite de leur vie. Un dicton a couru et court encore dans les différentes classes de notre société, surtout celle qui se croit assez instruite et informée pour prétendre à l'autonomie: «Depuis le concile, ce n'est plus comme avant, chacun prend ses décisions selon sa conscience.» Sans plus d'attention à l'éclairage et à la formation de cette conscience. Nous avons assisté alors à une sorte de défoulement chez un nombre étonnant de ces baptisés oublieux de leurs engagements prononcés lors de la réception du sacrement et renouvelés dans la suite. Il s'en est suivi un relâchement dans la foi, et plus encore dans la morale chrétienne issue de l'Évangile et dans la pratique religieuse; des religieux et des religieuses en nombre impressionnant se firent relever de leurs vœux sacrés, des prêtres de leurs obligations sacerdotales, ce que l'on n'avait jamais connu dans le passé, provoquant une diminution considérable des vocations et un appauvrissement de la pastorale; les époux infidèles, les divorces, les séparations, les mariages civils et les unions libres devinrent monnaie courante. Nous avions nous aussi notre monde pluraliste, mais au plan de la fidélité ou de l'infidélité à ses engagements sacrés. Et parmi 
ceux qui tiennent à demeurer officiellement dans le giron de l'Église, combien respectent sa morale issue de l'Évangile et promue par elle avec clarté et fermeté? Un cinquième? Nous ne croyons pas exagérer. Le glissement général vers la neutralité et le matérialisme est constant, même si la minorité de ceux qui tiennent sans équivoques est solide et édifiante. Notre peuple n'est plus ce qu'il a été et sans pessimisme, les conséquences de cette détérioration rapide de la pensée, du sentiment et de la conduite conformes à l'esprit du Christ peuvent aller jusqu'à l'assimilation dans le grand tout pluss nu moins païen. Dieu nous appelait à une toute autre vocation comme l'histoire le démontre péremptoirement.

\section{Conclusion}

Voilà où se situe et se vérifie l'importance de notre travail à nous qui sommes engagés dans l'étude et la publication de l'histoire de l'Église chez nous. L'enseignement de la doctrine révélée et de ses fruits savoureux dans notre vie est nécessaire, c'est incontestable, mais pour bien comprendrc cettc doctrine venue du ciel, trésor que nous ne pourrons jamais surestimer, il faut y ajouter la connaissance de l'histoire, de l'histoire de l'Église tout particulièrement. L'histoire, c'est la doctrine vécue, vue dans ses heureux effets. On comprend mieux et expose mieux la doctrine révélée quand on la voit dans la vie des croyants fervents, car Dieu illustre la doctrine qu'il nous présente pour notre conduite en nous la faisant voir avec ses fruits dans l'âme et la vie de ceux qui nous précèdent. Notre histoire est parmi les plus riches et les plus belles à ce point de vue qui est primordial parce qu'éternel. L'Église, au nom de Dieu, le met en évidence en notre temps où ce nous est si nécessaire, par les béatifications successives de nos chefs de file des années passées et en eux de notre petit peuple si méritant, si fidèle, et si généreux.

Notre rôle de membres de la Société canadienne d'histoire de l'Église catholique est donc des plus urgents, des plus précis et stimulants. Il consiste à apporter à notre peuple en ce temps où il se montre hésitant devant les voies qui s'ouvrent devant lui, une connaissance précise de la doctrine révélée et de son histoire, de son histoire en Église, cette Église qui l'a entouré de ses soins, fait vivre et survivre au long des années qu'il a traversées.

Chers membres et amis de la Société canadienne d'histoire de l'Église catholique, merci d'être venus ici à l'occasion du $150^{\mathrm{e}}$ anniversaire que nous célébrons. Que Dieu, le maître de l'histoire, de l'histoire de l'Église surtout, nous garde intimement liés les uns aux autres, nous inspire, nous guide, et nous soutienne pour son règne et le bien surnaturel de nos frères et sœurs! 